Psychological Medicine

http://journals.cambridge.org/PSM

Additional services for Psychological Medicine:

PSYCHOLOGICAL

Email alerts: $\underline{\text { Click here }}$

Subscriptions: $\underline{\text { Click here }}$

Commercial reprints: $\underline{\text { Click here }}$

Terms of use : $\underline{\text { Click here }}$

\title{
Suicide in bipolar disorder in a national English sample, 1996-2009: frequency, trends and characteristics
}

\author{
C. Clements, R. Morriss, S. Jones, S. Peters, C. Roberts and N. Kapur
}

Psychological Medicine / FirstView Article / April 2013, pp 1 - 10

DOI: 10.1017/S0033291713000329, Published online: 19 March 2013

Link to this article: http://journals.cambridge.org/abstract_S0033291713000329

How to cite this article:

C. Clements, R. Morriss, S. Jones, S. Peters, C. Roberts and N. Kapur Suicide in bipolar disorder in a national English sample, 1996-2009: frequency, trends and characteristics. Psychological Medicine, Available on CJO 2013 doi:10.1017/ S0033291713000329

Request Permissions : $\underline{\text { Click here }}$ 


\title{
Suicide in bipolar disorder in a national English sample, 1996-2009: frequency, trends and characteristics
}

\author{
C. Clements ${ }^{1 *}$, R. Morriss ${ }^{2}$, S. Jones ${ }^{3}$, S. Peters ${ }^{4}$, C. Roberts ${ }^{5}$ and N. Kapur ${ }^{1}$ \\ ${ }^{1}$ Centre for Mental Health and Risk, Institute of Brain, Behaviour and Mental Health, The University of Manchester, UK \\ ${ }^{2}$ Institute of Mental Health, The University of Nottingham, UK \\ ${ }^{3}$ Spectrum Centre for Mental Health Research, School of Health and Medicine, Lancaster University \\ ${ }^{4}$ School of Psychological Science, The University of Manchester, UK \\ ${ }^{5}$ Institute of Population Health, The University of Manchester, UK
}

Background. Bipolar disorder (BD) has been reported to be associated with high risk of suicide. We aimed to investigate the frequency and characteristics of suicide in people with BD in a national sample.

Method. Suicide in BD in England from 1996 to 2009 was explored using descriptive statistics on data collected by the National Confidential Inquiry into Suicide and Homicide by People with Mental Illness (NCI). Suicide cases with a primary diagnosis of $\mathrm{BD}$ were compared to suicide cases with any other primary diagnosis.

Results. During the study period 1489 individuals with BD died by suicide, an average of 116 cases/year. Compared to other primary diagnosis suicides, those with BD were more likely to be female, more than 5 years post-diagnosis, current/ recent in-patients, to have more than five in-patient admissions, and to have depressive symptoms. In BD suicides the most common co-morbid diagnoses were personality disorder and alcohol dependence. Approximately $40 \%$ were not prescribed mood stabilizers at the time of death. More than $60 \%$ of BD suicides were in contact with services the week prior to suicide but were assessed as low risk.

Conclusions. Given the high rate of suicide in BD and the low estimates of risk, it is important that health professionals can accurately identify patients most likely to experience poor outcomes. Factors such as alcohol dependence/misuse, personality disorder, depressive illness and current/recent in-patient admission could characterize a high-risk group. Future studies need to operationalize clinically useful indicators of suicide risk in BD.

Received 27 January 2012; Revised 13 November 2012; Accepted 29 January 2013

Key words: Bipolar disorder, mood disorders, suicide.

\section{Introduction}

Suicide is a major cause of premature mortality worldwide and its prevention is a clinical and policy priority. Individuals with bipolar disorder (BD) are thought to be at particularly high risk and it has been suggested that between $12 \%$ and $19 \%$ of people diagnosed with BD die by suicide (Guze \& Robins, 1970; Goodwin \& Jamison, 1990; Harris \& Barraclough, 1997). However, data from more recent studies have cast some doubt on the validity of these figures. Estimates of suicide incidence have tended to be lower (Tondo et al. 2003; Rihmer, 2005), possibly as a consequence of changes in diagnostic criteria over time, the inclusion of bipolar subtypes and less focus on in-patient

* Address for correspondence: C. Clements, Centre for Mental Health and Risk, Institute of Brain, Behaviour and Mental Health, The University of Manchester, UK.

(Email: caroline.v.clements@manchester.ac.uk) populations. In a study of absolute risk of suicide after hospital contact for mental disorder, Nordentoft et al. (2011) followed up individuals over 36 years and found that the highest risk was among men with BD: $8 \%$ died by suicide during the follow-up period. For women with BD the risk was $5 \%$ and was the second highest risk group behind only schizophrenia. These figures are similar to those presented by Angst et al. (2002), who found that $8 \%$ of people with BD died by suicide over a follow-up period of more than 40 years. In a review of studies of suicide by individuals with a current major depressive episode, Rihmer (2005) reported that $44 \%$ may have had a diagnosis of bipolar II disorder (BD II). In two prospective studies, Tondo et al. $(2003,2007)$ found that the rate of suicide in $\mathrm{BD}$ was $0.25 \% /$ year and $0.4 \%$ /year respectively. The lack of consensus is likely to be a consequence of the different methodologies used in these studies. Accurately estimating the rate of suicide in $\mathrm{BD}$ is further complicated by the continuing opacity 
of the prevalence of $\mathrm{BD}$ itself, with estimates ranging from $0.5 \%$ to $2.4 \%$ in studies of the general population (Mitchell et al. 2004; Merikangas et al. 2007, 2011; Lee et al. 2009), and could be as high as $3-4 \%$ for BD II (Merikangas \& Lamers, 2012). Perhaps unsurprisingly, given this context, few studies have examined temporal trends in BD suicides.

Several studies have sought to identify which bipolar patients are most at risk of suicide but results have proved limited and contradictory. Marangell et al. (2006) carried out a prospective study of bipolar patients in the USA and found that history of suicide attempt and percentage days depressed in the previous year were related to subsequent suicidal behaviour. Other studies have also identified history of suicide attempt as a risk factor for suicide in BD (Rihmer, 2007), along with male gender (Hawton et al. 2005) and expressed hopelessness (Tondo et al. 2003). However, these characteristics are also common in general population suicides and are therefore unlikely to be related specifically to a diagnosis of BD.

Previous work has been subject to several methodological limitations; studies have typically recruited small samples, included few events, or have been carried out within a single treatment centre or geographical area (Tondo et al. 2003; Hawton et al. 2005). Research on incidence and rates of suicide in BD has often been restricted to a specific bipolar subtype or more seriously ill hospitalized patients (Baldessarini \& Jamison, 1999; Fagiolini et al. 2004). Follow-up periods are often short and might distort the risk of suicide in $\mathrm{BD}$ as risk may be increased in the early stages of $\mathrm{BD}$ and diagnoses may change over time (for example, bipolar is often misdiagnosed initially as unipolar depression) (Goodwin \& Jamison, 1990).

The prevention of suicide, particularly among highrisk groups such as those with mental illness, is an important public health aim in many countries (US Public Health Service, 1999; Department of Health, 2002). Reliable baseline statistics are essential in tracking progress but the comparative lack of good quality international data on suicide in BD makes it difficult to assess the impact of suicide prevention strategies in this group. More reliable estimates of the frequency of suicide in BD and further clarification of the key characteristics associated with suicide in BD would be of use to clinicians, service providers and policy makers.

\section{Aims}

The aim of this study was to describe the frequency, trends over time, and characteristics of those with BD who died by suicide in England, using data from a large national database. The specific objectives were to: (1) describe the frequency of suicide in BD in a clinical population; (2) identify any trends over time in the number of bipolar suicide deaths; and (3) describe the demographic, clinical and management characteristics of people with a primary diagnosis of BD who died by suicide, and to compare them to suicides by people with other primary diagnoses.

\section{Method}

\section{The National Confidential Inquiry into Suicide and Homicide by People with Mental Illness (NCI)}

Our analyses used data from the suicide database of the NCI (Appleby et al. 2006; Hunt et al. 2006). Data collection by the NCI involves three stages. In stage 1 the NCI collects basic information on a complete national sample of suicide deaths and deaths that have received an open verdict at coroner's inquest for all individuals aged $\geqslant 10$ years, from the Office for National Statistics (ONS) for England and Wales. It is convention in the UK to include open verdicts in official statistics and research studies, as the majority of these are suicide deaths (O'Donnell \& Farmer, 1995), and excluding cases given open verdicts may result in a $50 \%$ underestimate in the incidence of suicide (Linsley et al. 2001). All open verdicts are included unless there is a clear record that suicide was not considered as a cause of death at inquest. In stage 2 the $\mathrm{NCI}$ identifies suicides that were in contact with mental health services in the 12 months prior to death by contacting hospitals and community trusts providing these services in the deceased's district of residence. If records show the deceased was in contact with services, they become an 'inquiry case'. In stage 3, for all 'inquiry cases', the consultant psychiatrist responsible for the care of the patient is identified and sent a copy of the NCI suicide questionnaire to complete. The suicide questionnaire collects information on social/demographic characteristics, clinical history, details of the suicide, details of care and final contact with services, and the respondents' views on prevention.

Data from returned suicide questionnaires are entered onto the NCI suicide database, which includes data on inquiry cases from 1996 onwards. The NCI suicide questionnaire has a response rate of more than 97\% (Appleby et al. 2012) and has been shown to be a reliable data collection tool (Windfuhr et al. 2008).

\section{NCI BD sample}

Unless stated otherwise, the BD suicide sample used in the analyses includes all cases on the NCI suicide database with a primary diagnosis of BD from England. Primary and secondary diagnoses are collected 
routinely as part of the NCI suicide questionnaire. Primary diagnosis is considered to be the 'main' psychiatric diagnosis and is determined by the responding clinician. Diagnostic categories are concordant with ICD-10 classifications. Therefore, the diagnostic group 'bipolar disorder' on the NCI suicide database encompasses the same groups as the ICD-10 BD category (F31) and includes BD I, BD II, and BD not otherwise specified (NOS). Respondents may use a combination of case-note review, consultation with other members of the mental health team and clinical judgement based on their own knowledge of the patient in reporting primary and secondary diagnoses.

\section{Analysis}

All statistical analyses were conducted using SPSS 15.0 for Windows (SPSS Inc., USA), apart from trend tests, which were carried out using Stata/IC 11.0 for windows (StataCorp LP, USA).

\section{Trends}

Poisson regression was used to carry out trend tests for significant increases or decreases in BD suicides over time. Tests were run for the whole NCI bipolar sample and separately for males, females and age groups (the four age groups were those commonly used in the work of the NCI: $\leqslant 24,25-44,45-64$ and $\geqslant 65$ years). We also formally tested for interaction between bipolar and general population suicide deaths, and between different age groups for the bipolar sample.

\section{Characteristics of suicide in $B D$}

Simple descriptive statistics were used to describe the demographic, treatment and clinical characteristics of the bipolar suicides. Items were compared between BD suicides and other primary diagnosis suicides. Any cases with unknown items were removed from the analysis of that item; therefore, the denominator in each analysis is the number of valid cases for each item. The number of valid responses included for each item are displayed as a percentage of the total number of cases. Where possible, variables were combined to create more comprehensive categories and to reduce the proportion of missing data (e.g. individual antidepressant categories were combined to create a single antidepressant variable). Pearson's $\chi^{2}$ tests of association were used, for two by two tables the continuity correction is given, odds ratios (ORs) and associated $95 \%$ confidence intervals (CIs) are also presented. Because multiple testing was used, a $p$ value of 0.01 was selected to assess statistical significance. Age and gender were regarded as possible explanatory variables rather than confounders and so were not adjusted for in the primary analyses; however, secondary analyses adjusting all ORs for age and gender were carried out.

\section{Results}

There were 1489 BD suicides in our sample. This represented just less than $10 \%$ of all suicide deaths on the NCI database for the study period (9.6\% of 15465 valid cases). The average number of BD suicides per year between 1997 and 2007 (when data were most complete) was 116 . The average frequency of BD suicide per year was 65 for males and 52 for females.

\section{Trends over time}

There were no significant trends in the frequency of BD suicides over time [incidence rate ratio (IRR) $0.99,95 \%$ CI $0.97-1.00, p=0.15]$ whereas general population suicides over the same time period decreased significantly (IRR 0.98, 95\% CI 0.98-0.98, $p<0.01$ ). There was no significant increase or decrease in frequency of BD suicides for females (IRR 1, 95\% CI 0.97-1.02, $p=0.79$ ) or males (IRR 0.98, 95\% CI 0.96-1.00, $p=0.08$ ). A test of interaction between BD suicides and all other suicides in the general population was not significant $\left(\chi^{2}=0.13\right.$, $\mathrm{df}=1, p=0.72$ ), suggesting that the failure to detect significant falls in suicide in the bipolar sample could have been due to smaller numbers. With respect to age, trend tests showed significant downward trends in the frequency of suicide for the under-24 age group (IRR 0.84, 95\% CI 0.77-0.93, $p<0.001$ ) and the 25-44 age group (IRR 0.97, 95\% CI 0.94-0.99, $p=$ 0.015). There were no significant trends in the older age groups. A test of interaction confirmed that the decline in suicides over time was significantly different between age groups $\left(\chi^{2}=18.3, \mathrm{df}=3, p<0.001\right)$.

\section{Characteristics of the sample}

\section{Demographics and secondary diagnoses}

Table 1 shows the demographic and diagnostic characteristics of BD suicides compared to other primary diagnosis suicides. BD suicides were older and less likely to be male. BD suicides were less likely than other primary diagnosis suicides to have several characteristics that are known risk factors for suicide (e.g. homelessness and a history of previous suicidal behaviour). BD suicides were more likely to have had their primary diagnosis for more than 5 years. Overall, those with BD were less likely than other patients to have a formal secondary diagnosis (particularly those related to depression or anxiety). The most common secondary diagnoses in those with $\mathrm{BD}$ who died by suicide were personality disorder and alcohol dependence, together accounting for nearly one-fifth of cases. 
Table 1. Demographic and clinical characteristics for suicides with a primary diagnosis of bipolar disorder (BD) compared to suicides with any other primary diagnosis

\begin{tabular}{|c|c|c|c|c|}
\hline $\begin{array}{l}\text { Variable (\% valid responses) } \\
(n=15465)\end{array}$ & $\begin{array}{l}\mathrm{BD} \\
(n=1489) \\
n(\%)\end{array}$ & $\begin{array}{l}\text { All other diagnoses } \\
(n=13976) \\
n(\%)\end{array}$ & OR $(95 \% \mathrm{CI})$ & $p$ value \\
\hline \multicolumn{5}{|l|}{ Age group (98) } \\
\hline$\leqslant 24$ years & $57(3.8)$ & $1106(8.1)$ & $0.45(0.35-0.59)$ & \multirow[t]{4}{*}{$<0.01$} \\
\hline 25-44 years & $641(43.0)$ & $6297(46.0)$ & $0.89(0.80-0.99)$ & \\
\hline 45-64 years & $635(42.6)$ & $4574(33.4)$ & $1.48(1.33-1.65)$ & \\
\hline$\geqslant 65$ years & $156(10.5)$ & $1701(12.4)$ & $0.82(0.69-0.98)$ & \\
\hline Male (98) & $833(55.9)$ & $9113(66.6)$ & $0.64(0.57-0.71)$ & $<0.01$ \\
\hline \multicolumn{5}{|l|}{ Ethnic origin (93) } \\
\hline White & $1373(93.2)$ & $12446(93.0)$ & $1.03(0.84-1.28)$ & \multirow[t]{4}{*}{0.17} \\
\hline Black African/Caribbean & $23(1.6)$ & $289(2.2)$ & $0.72(0.47-1.10)$ & \\
\hline Indian/Pakistani/Bangladeshi & $43(2.9)$ & $302(2.3)$ & $1.30(0.94-1.80)$ & \\
\hline Chinese & $2(0.1)$ & $26(0.2)$ & $0.70(0.17-2.95)$ & \\
\hline \multicolumn{5}{|l|}{ Marital status (96) } \\
\hline Married or cohabiting & $469(31.8)$ & $3976(29.6)$ & $1.11(0.99-1.24)$ & \multirow[t]{3}{*}{$<0.01$} \\
\hline Single or divorced & $935(63.3)$ & $8537(63.6)$ & $0.99(0.89-1.11)$ & \\
\hline Widowed & $72(4.9)$ & $909(6.8)$ & $0.71(0.55-0.90)$ & \\
\hline \multicolumn{5}{|l|}{ Employment status (94) } \\
\hline Employed & $268(18.3)$ & $2479(18.8)$ & $0.97(0.84-1.11)$ & \multirow[t]{3}{*}{$<0.01$} \\
\hline Unemployed & $547(37.4)$ & $5481(41.6)$ & $0.84(0.75-0.94)$ & \\
\hline Other & $649(44.3)$ & $5228(39.6)$ & $1.21(1.09-1.35)$ & \\
\hline \multicolumn{5}{|l|}{ Living arrangements (94) } \\
\hline Living alone & $667(45.4)$ & $5596(42.2)$ & $1.09(0.98-1.21)$ & \multirow[t]{4}{*}{$<0.01$} \\
\hline Living with family & $660(44.9)$ & $6119(46.2)$ & $0.94(0.84-1.05)$ & \\
\hline Homeless & $14(1.0)$ & $271(2.0)$ & $0.43(0.26-0.71)$ & \\
\hline Other & $128(8.7)$ & $1269(9.6)$ & $0.94(0.70-1.14)$ & \\
\hline Previous self-harm (96) & $938(63.9)$ & 9039 (67.3) & $0.86(0.77-0.97)$ & 0.01 \\
\hline History of violence (95) & $314(21.4)$ & $2754(20.7)$ & $1.04(0.91-1.19)$ & 0.59 \\
\hline \multicolumn{5}{|l|}{ Method of suicide (96) } \\
\hline Self-poisoning & $394(26.6)$ & $3885(28.6)$ & $0.90(0.80-1.01)$ & \multirow[t]{4}{*}{$<0.01$} \\
\hline Hanging & $527(35.6)$ & $4973(36.6)$ & $0.95(0.85-1.06)$ & \\
\hline Jumping & $263(17.8)$ & $1974(14.5)$ & $1.26(1.10-1.46)$ & \\
\hline Other & $295(19.9)$ & $2766(20.3)$ & $0.98(0.85-1.12)$ & \\
\hline \multicolumn{5}{|l|}{ Duration of primary diagnosis (97) } \\
\hline$<1$ year & $147(9.9)$ & $2887(21.5)$ & $0.40(0.34-0.48)$ & \multirow[t]{3}{*}{$<0.01$} \\
\hline $1-5$ years & $276(18.6)$ & $3793(28.2)$ & $0.58(0.51-0.67)$ & \\
\hline$>5$ years & $1057(71.4)$ & $6766(50.3)$ & $2.47(2.19-278)$ & \\
\hline \multicolumn{5}{|l|}{ Secondary diagnoses (96) } \\
\hline $\mathrm{BD}$ & 0 & $89(0.7)$ & - & \multirow[t]{11}{*}{$<0.01$} \\
\hline Depressive illness & $70(4.8)$ & $1675(12.4)$ & $0.35(0.28-0.45)$ & \\
\hline Anxiety/phobia/panic disorder/OCD & $44(3.0)$ & $1125(8.3)$ & $0.30(0.25-0.46)$ & \\
\hline Alcohol dependence & $116(7.9)$ & $974(7.2)$ & $1.11(0.91-1.35)$ & \\
\hline Drug dependence & $51(3.5)$ & $642(4.8)$ & $0.72(0.54-0.97)$ & \\
\hline Personality disorder & $143(9.8)$ & $1174(8.7)$ & $1.14(0.95-1.36)$ & \\
\hline Adjustment disorder & $28(1.9)$ & $550(4.1)$ & $0.46(0.31-0.67)$ & \\
\hline Alcohol misuse but not dependence & $59(4.0)$ & $526(3.9)$ & $1.04(0.79-1.36)$ & \\
\hline Drug misuse but not dependence & $31(2.1)$ & $307(2.3)$ & $0.93(0.64-1.35)$ & \\
\hline Other & $48(3.3)$ & $507(3.8)$ & $0.87(0.64-1.17)$ & \\
\hline No secondary diagnosis & $874(59.7)$ & $5927(43.9)$ & $1.89(1.70-2.11)$ & \\
\hline
\end{tabular}

OCD, Obsessive-compulsive disorder; OR, odds ratio; CI, confidence interval. 
Table 2. Treatment characteristics for suicides with a primary diagnosis of bipolar disorder (BD) compared to suicides with any other primary diagnosis

\begin{tabular}{|c|c|c|c|c|}
\hline $\begin{array}{l}\text { Care and treatment characteristics } \\
\text { (\% valid responses) } \\
(n=15465)\end{array}$ & $\begin{array}{l}\mathrm{BD} \\
(n=1489) \\
n(\%)\end{array}$ & $\begin{array}{l}\text { All other } \\
\text { diagnoses } \\
(n=13976) \\
n(\%)\end{array}$ & OR $(95 \% \mathrm{CI})$ & $p$ value \\
\hline In-patient at time of suicide (98) & $286(19.2)$ & $1835(13.4)$ & $1.54(1.34-1.76)$ & $<0.01$ \\
\hline Suicide within 3 months of discharge from in-patient care (84) & $339(28.2)$ & $2772(23.4)$ & $1.28(1.12-1.47)$ & $<0.01$ \\
\hline One to five previous admissions to in-patient care (94) & $828(57.2)$ & $7574(57.6)$ & $0.98(0.88-1.10)$ & 0.78 \\
\hline More than five admissions to in-patient care (94) & $469(32.4)$ & $1754(13.3)$ & $3.11(2.76-3.51)$ & $<0.01$ \\
\hline ECT $(76)$ & $12(1.1)$ & $73(0.7)$ & $1.53(0.83-2.83)$ & 0.24 \\
\hline Seeing drug and/or alcohol services (94) ${ }^{\mathrm{a}}$ & $39(5.9)$ & $701(11.9)$ & $0.47(0.33-0.65)$ & $<0.01$ \\
\hline Receiving psychological treatment (74) & $169(15.0)$ & $1660(16.0)$ & $0.92(0.78-1.10)$ & 0.38 \\
\hline Prescribed oral typical antipsychotic drugs (73) & $205(18.3)$ & $1285(12.6)$ & $1.55(1.32-1.83)$ & $<0.01$ \\
\hline Prescribed oral atypical antipsychotic drugs (73) & $435(38.9)$ & $2683(26.3)$ & $1.78(1.57-2.03)$ & $<0.01$ \\
\hline Prescribed lithium or mood stabilizer (73) & $654(58.2)$ & $707(6.9)$ & $18.77(16.30-21.62)$ & $<0.01$ \\
\hline Prescribed any antidepressant (71) & $704(60.0)$ & $6606(66.1)$ & $0.77(0.68-0.87)$ & $<0.01$ \\
\hline Non-compliant with medication in the month before death (87) & $254(18.2)$ & $2105(17.2)$ & $1.07(0.93-1.24)$ & 0.38 \\
\hline
\end{tabular}

ECT, Electro-convulsive therapy; OR, odds ratio; CI, confidence interval.

${ }^{a}$ Question added to National Confidential Inquiry into Suicide and Homicide by People with Mental Illness (NCI) questionnaire in 2003; only cases where year of death was 2003 or later were included in the analysis (sample comprised 660 BD diagnosis, $n=5896$ all other diagnosis).

\section{Care and management characteristics (Table 2)}

Compared to other primary diagnosis suicides, BD suicides were more likely to have been current or recent in-patients and to have had more than five previous admissions to in-patient care. BD suicides were less likely than other primary diagnosis suicides to be in contact with drug and alcohol services. BD suicides were slightly more likely to be prescribed typical or atypical antipsychotic drugs than the comparison group, and much more likely to have been prescribed lithium or other mood stabilizers. Overall, just over half of BD suicides had been prescribed mood stabilizers. Of those prescribed mood stabilizers who died by self-poisoning $(179,27.4 \%)$, the overdose included these drugs in only $25(14.0 \%)$ cases.

\section{Clinical characteristics at last contact before suicide} (Table 3)

BD suicides were more likely to have been seen by mental health services in the 7 days prior to suicide than those with other primary diagnoses. BD suicides were also more likely to have evidence of depressive symptoms at last contact, but less likely than those with other primary diagnosis to have evidence of hostility at last contact. The majority of cases across both groups were considered to be at low or no immediate risk of suicide.
When we adjusted the ORs in Tables 1-3 for age and gender, there was little impact on our findings (data available from authors).

\section{Discussion}

\section{Main findings}

This study describes the largest detailed sample of suicide deaths by individuals with BD in the international literature to date. In our sample nearly $10 \%$ of current psychiatric patients who died by suicide had a primary diagnosis of BD. Trend tests suggest that the decline in BD suicide deaths was not statistically significant but this could have been due to small numbers. There was some evidence of a decrease in the number of BD suicide deaths by younger patients.

There was a higher proportion of females among BD suicides than among other primary diagnosis suicides. BD suicides were more than twice as likely as those with other primary diagnoses to have been diagnosed more than 5 years prior to the suicide. Demographic and social factors among those with BD showed little difference compared with those with other primary diagnoses. Personality disorder and alcohol dependence were the most common secondary diagnoses in the BD group. BD suicides had a distinct pattern in relation to accessing in-patient care and just less than half were current or recent in-patients at the 
Table 3. Clinical characteristics at last contact with mental health services for suicides with a primary diagnosis of bipolar disorder (BD) compared to suicides with any other primary diagnosis

\begin{tabular}{|c|c|c|c|c|}
\hline $\begin{array}{l}\text { Clinical characteristics at last contact } \\
\text { (\% valid responses) } \\
(n=15465)\end{array}$ & $\begin{array}{l}\mathrm{BD} \\
(n=1489) \\
n(\%)\end{array}$ & $\begin{array}{l}\text { All other diagnoses } \\
(n=13976) \\
n(\%)\end{array}$ & OR $(95 \% \mathrm{CI})$ & $p$ value \\
\hline \multicolumn{5}{|c|}{ Time between last contact and suicide (97) } \\
\hline$<24 \mathrm{~h}$ & $349(23.7)$ & $2589(19.2)$ & $1.30(1.15-1.48)$ & \multirow[t]{5}{*}{$<0.01$} \\
\hline $1-7$ days & $555(37.6)$ & $3988(29.6)$ & $1.43(1.28-1.60)$ & \\
\hline $1-4$ weeks & $312(21.2)$ & $3153(23.4)$ & $0.88(0.77-1.00)$ & \\
\hline 5-13 weeks & $151(10.2)$ & $1746(13.0)$ & $0.77(0.65-0.91)$ & \\
\hline$>13$ weeks & $108(7.3)$ & $1984(14.7)$ & $0.46(0.37-0.56)$ & \\
\hline Evidence of emotional distress (94) & $467(32.3)$ & $4565(34.8)$ & $0.90(0.80-1.01)$ & 0.07 \\
\hline Evidence of depressive episode (94) & $567(39.2)$ & $3859(29.5)$ & $1.54(1.38-1.72)$ & $<0.01$ \\
\hline Evidence of hostility (94) & $62(4.3)$ & $786(6.0)$ & $0.70(0.54-0.92)$ & 0.01 \\
\hline Evidence of hopelessness (93) & $229(16.0)$ & $1950(15.1)$ & $1.07(0.92-1.24)$ & 0.39 \\
\hline \multicolumn{5}{|l|}{ Immediate suicide risk (92) } \\
\hline No risk & $417(29.2)$ & $3842(30.0)$ & $0.96(0.85-1.09)$ & \multirow[t]{4}{*}{0.64} \\
\hline Low & $813(57.0)$ & $7162(56.0)$ & $1.04(0.93-1.16)$ & \\
\hline Moderate & $173(12.1)$ & $1520(11.9)$ & $1.02(0.87-1.21)$ & \\
\hline High & $24(1.7)$ & $270(2.1)$ & $0.79(0.52-1.21)$ & \\
\hline
\end{tabular}

time of the suicide. Most had previously been admitted to in-patient care and were three times more likely than those with other primary diagnosis to have had more than five previous in-patient admissions. Mood stabilizers were the most commonly prescribed pharmacological treatment for those with BD; however, given the possible anti-suicidal properties of lithium (Baldessarini et al. 2006), an important finding was that more than $40 \%$ of cases were not prescribed mood stabilizers. Data for this variable were not complete (73\% complete). This finding should therefore be interpreted cautiously, although we suspect that those not prescribed mood stabilizers would be overrepresented in the missing data group. In this case the proportion of individuals not prescribed appropriate medication might be even higher. Just over $60 \%$ of patients with BD had been in contact with mental health services in the 7 days prior to the suicide, and just under half of these were seen within 24 hours of the suicide. Almost $90 \%$ of BD suicides were assessed as being at no or low immediate risk of suicide when they were seen (although this was not dissimilar to those with other primary diagnoses).

\section{Findings in relation to previous research}

The results of this study are consistent with previous research on factors found to be associated with completed suicide in BD (Dalton et al. 2003; Leverich et al. 2003; Tondo et al. 2003; Rihmer, 2009). Our data confirm that suicide in BD is associated with a high number of previous admissions to in-patient care
(Leverich et al. 2003), although the reasons for admission were not available. The number of bipolar cases with substance misuse (Lopez et al. 2001; Tondo et al. 2003; Oquendo \& Mann, 2006) and/or anxiety disorder (Angst et al. 2002; Leverich et al. 2003; Simon et al. 2007) was lower than might have been expected given the prevalence of co-morbid substance and anxiety disorders typically found in BD populations (Goodwin \& Jamison, 1990). It is possible that this was a recording bias. However, our study was restricted to a clinical subgroup of people with BD who died by suicide and previous work has suggested that substance/ alcohol use is not strongly related to suicide in these individuals (Hawton et al. 2005). We should also bear in mind that the data in Table 1 refer to formal secondary diagnoses made by the treating clinical team. Although lower than expected, alcohol use/dependence was one of the most common secondary diagnoses in BD suicides and therefore may have been an important contributory factor. Less than $40 \%$ of BD suicides had evidence of depressive symptoms at their last contact with services before the suicide. This is in contrast to many studies of suicide attempt in BD, where structured psychiatric assessments have found that depressive symptoms and depressive episode are prominent. The lower than expected proportion of cases with depression in our results could be due to the particular characteristics of our clinical sample, a reflection of the time interval between being seen and death, or it could be an indication of a crucial under-recognition of depression among this group. Risk of suicide is thought to be higher at younger ages and earlier in the course 
of BD (Goodwin \& Jamison, 1990). However, our results show that $\mathrm{BD}$ suicides commonly took place more than 5 years post-diagnosis and most frequently by people in the 25-64-year age groups, and suicides by people aged between 45 and 64 years were much more common in the BD group than in the other primary diagnosis group. We found that the majority of cases included were considered to be at 'low risk' for suicide at last contact with services. This is consistent with the results of psychological autopsy studies, which have shown that suicidal intent is rarely communicated when the individual is seen by a health-care professional shortly before the suicidal act, although it may be communicated earlier to friends or family members (Isometsä et al. 1994, 1995).

\section{Methodological issues}

Not all those with BD who die by suicide will be in contact with services in the 12 months before death (Merikangas \& Pato, 2009), and not all those in contact with services will be appropriately diagnosed with BD (Dunner, 2003; Benazzi, 2006). The characteristics of our sample may not reflect the characteristics of those with BD with no service contact prior to death. A study from The Netherlands by ten Have et al. (2002) found that the most common reason for a lack of contact with mental health services was lower severity of BD symptoms; therefore our sample may be biased towards the more seriously ill. It would have not been feasible as part of this national study to collect detailed data on all individuals with BD who had not been in contact with mental health services.

Data used in the analyses were collected from clinicians after the suicide had occurred. Completion of the NCI suicide questionnaire relies on the accuracy of case-notes and the clinicians' knowledge of the patient. The clinicians were therefore not blind to patient outcome when completing the questionnaire and it is possible that this could influence results, particularly those relating to care or treatment before death.

Allocation to the BD suicide group was dependent on the recording of primary diagnosis by responding clinicians and it is possible that, where there were multiple co-morbidities, primacy may have been attributed incorrectly. There were 89 cases with a secondary diagnosis of BD, all of which had a primary diagnosis of schizophrenia; we adopted a conservative approach and included these in the other primary diagnosis group, which may have reduced between-group differences. We also carried out a post-hoc sensitivity analysis including these 89 individuals in our BD suicide group. There was little effect overall on the results.

It is possible that the clinician completing the questionnaire was not the professional with whom the last contact was made and consequently variables relating to clinical state might have been underreported and found less frequently than expected (e.g. evidence of depressive symptoms). However, clinicians generally use patient records along with their personal knowledge and recollection of the patient when filling in the NCI questionnaire, and it would be unusual for significant changes in mood state not to be recorded as part of the clinical record.

There are some potential issues with missing data on the NCI database and therefore the results presented should be interpreted with caution. The majority of variables were more than $90 \%$ complete. Patient treatment variables had greater levels of missing data. In most cases this was because the clinician completing the questionnaire left some fields blank, but some cases were historical artefacts due to the evolving nature of the suicide questionnaire and the addition of new questions over time that could not be backcoded for older cases (these have been adjusted where possible; for example, access to drug and alcohol services was added in 2003).

This study was descriptive in nature. Although it was possible to identify characteristics that are common in suicide in BD, it was not possible to comment on the aetiology of these factors, or inter-relationships that may exist between them. As some of these risk factors may have been consequences of care and not true risk factors, we did not undertake a multivariate analysis.

\section{Clinical and research implications}

Frequency and characteristics of suicide in $B D$

Suicide prevention is a priority for services (Appleby et al. 2012). The results of this study show that those with BD frequently die by suicide, and our findings are likely to have underestimated the magnitude of this risk. Overall, the frequency of bipolar suicide seems to have remained relatively stable over time, which is in contrast to falling rates of suicide in the English general population. It may be that some of the societal determinants of suicide have less of an impact in this clinical population, where illness-related factors may be more relevant. The possibility that individual clinical groups are not benefiting from an overall decline in suicide raises issues of equity and this warrants specific exploration in future studies. Nevertheless, the lack of a significant decrease in suicide rates by those with $\mathrm{BD}$ could be a power issue reflecting the comparatively small numbers of deaths in this group. The evident stability of BD suicide deaths could also be a consequence of the improved diagnosis of $\mathrm{BD}$ and perhaps of BD II in particular. This might have caused an increase in BD suicides as people who 
would previously have been diagnosed with unipolar depressive disorder are moved into the BD category.

Although several demographic and social characteristics in our BD sample were similar to those in suicides in general and psychiatric populations, we did find that women were over-represented. There is little consensus on the role of gender in relation to suicide in BD, and this might reflect a greater long-term suicide risk in women than in men (Pompili et al. 2009; Gonda et al. 2012). Cohort studies of those with mental illness often describe the risk of suicide as highest at the time of diagnosis, with the risk subsequently diminishing over time (Goodwin \& Jamison, 1990; ten Have et al. 2002). We found that the majority of BD suicides in fact took place at least 5 years after diagnosis. In addition, those with BD were more likely to die by suicide in middle-age than those with other primary diagnoses. These findings suggest that risk of suicide in BD may be relatively persistent.

\section{Implications for services and treatment}

Although there were similar levels of co-morbid alcohol dependence in the BD group and in those with other primary diagnoses, the BD group were less likely to be in contact with alcohol services, highlighting a possible deficiency in the provision of dual diagnosis services. However, policy changes have sought to address this (Department of Health, 2001; CSIP, 2008). Over a third of BD suicides in this study were not prescribed lithium or another mood stabilizer, although there were some missing data for this variable. Given the increased risk of suicide that seems to accompany a diagnosis of $\mathrm{BD}$ and the strong evidence for the protective effect of lithium (Tondo et al. 2003; Angst et al. 2005; Rihmer, 2005), this might be considered a key treatment in long-term management.

\section{Risk assessment}

A clinically important result was that the majority of patients with BD were seen by mental health services during the week before the suicide, and nearly a quarter within the 24 hours immediately preceding it, providing a potential opportunity for services to intervene. However, nine out of $10 \mathrm{BD}$ suicides were assessed as being at no or low risk at last contact. These data suggest that clinical assessment of suicide risk may not be accurately identifying at-risk $\mathrm{BD}$ patients, or that patients with BD are subject to rapid changes in mental state consistent with the hypothesis that suicidal behaviour in BD is associated with impulsivity (Rihmer, 2007). However, assessment of suicide risk reported on the NCI questionnaire may also be influenced by other considerations such as recall bias, defensiveness in the reporting of this item, or the result of adaptation to risk by clinical staff through continued exposure to high-risk patients. It is also possible that recognition of high risk could trigger the implementation of interventions to lessen that risk and thereby prevent suicide, and so by default the majority of completed suicides by psychiatric patients in contact with services would be from individuals not identified as being at risk. Although this explanation is heuristically appealing, questions remain regarding why these cases of completed suicide were not assessed as 'at risk', and whether there are indicators of risk that are being missed in current assessments.

It is important that health professionals are able to accurately identify those patients who might be most at risk. Factors such as alcohol dependence/misuse, personality disorder, depressive episode, multiple psychiatric admissions and current or recent admission could characterize such a high-risk group. In our sample of BD suicide deaths, $75 \%$ had one or more of these factors, $34 \%$ had two or more, $8 \%$ had three or more, and less than $1 \%$ had four. In terms of risk management, a reduction in the emphasis placed on traditional indicators of risk, such as social circumstances and recent diagnosis, and an increase in the emphasis on diagnosis-specific factors may increase the utility of assessments. Ideally, clinically useful indicators of suicide risk that can be operationalized need to be identified in future studies. However, the identification of a high-risk group with $\mathrm{BD}$ on the basis of factors associated with suicide in this sample would be premature as two-thirds of completed suicide had less than two of these risk factors. More work is required to determine the causes of suicide in BD and to explore how risk factors interact to precipitate suicidal behaviour.

\section{Acknowledgements}

We acknowledge the help of the NCI. This article presents independent research commissioned by the National Institute for Health Research (NIHR) under its Programme Grants for Applied Research funding scheme (RP-PG-0407-10389). The views expressed in this article are those of the authors and not necessarily those of the National Health Service (NHS), the NIHR or the Department of Health.

\section{Declaration of Interest}

None.

\section{References}

Angst F, Stassen HH, Clayton PJ, Angst J (2002). Mortality of patients with mood disorders: follow-up over 34-38 years. Journal of Affective Disorders 68, 167-181. 
Angst J, Angst F, Gerber-Werder R, Gamma A (2005). Suicide in 406 mood-disorder patients with and without long-term medication: a 40 to 44 years' follow-up. Archives of Suicide Research 9, 279-300.

Appleby L, Shaw J, Kapur N, Windfuhr K, Ashton A, Swinson N, While D, Lowe R, Bickley H, Flynn S, Hunt I, McDonnell S, Pearson A, Da Cruz D, Rodway C, Roscoe A, Saini P, Turnbull P, Burns J, Hadfield K, Stones P (2006). Avoidable deaths: five-year report of the National Confidential Inquiry into Suicide and Homicide by People with Mental Illness (http://www.medicine. manchester.ac.uk/cmhr/centreforsuicideprevention/nci/ reports/avoidable_deaths_full_report_december_2006.pdf). Accessed 20 August 2011.

Appleby L, Shaw J, Kapur N, Windfuhr K, Williams A, Swinson N, Hunt I, Flynn S, Bickley H, Rodway C, Roscoe A, Turnbull P, Saini P, Da Cruz D, Pearson A, While D, Lowe R, Burns J, Hadfield K, Stones P, Clarke P (2012). National Confidential Inquiry into Suicide and Homicide by People with Mental Illness: Annual Report England and Wales (http://www.medicine.manchester.ac. $\mathrm{uk} / \mathrm{cmhr} /$ centreforsuicideprevention/nci/reports/ annual_report_2010.pdf). Accessed 20 August 2011.

Baldessarini RJ, Jamison KR (eds) (1999). Effects of medical interventions on suicidal behaviour. Journal of Clinical Psychiatry 60 (Suppl. 2), 1-122.

Baldessarini RJ, Tondo L, Davis P, Pompili M, Goodwin FK, Hennen J (2006). Decreased risk of suicides and attempts during long-term lithium treatment: a meta-analytic review. Bipolar Disorders 8, 625-639.

Benazzi F (2006). Mood patterns and classification in bipolar disorder. Current Opinion in Psychiatry 19, 1-8.

CSIP (2008). Dual diagnosis: developing capable practitioners to improve services and increase positive service user experience. Department of Health and Care Services Improvement Partnership: London. (www.nmhdu.org.uk/ silo/files/capable-practitioners.pdf). Accessed 22 August 2011.

Dalton EJ, Cate-Carter TD, Mundo E, Parikh S, Kennedy J (2003). Suicide risk in bipolar patients: the role of co-morbid substance use disorders. Bipolar Disorders 5, 58-61.

Department of Health (2001). Mental health policy implementation guide: dual diagnosis good practice guide (www.dh.gov.uk/en/Publicationsandstatistics/Publications/ PublicationsPolicyAndGuidance/DH_4009350). Accessed 29 August 2011.

Department of Health (2002). National suicide prevention strategy for England (www.dh.gov.uk/en/

Publicationsandstatistics/Publications/ PublicationsPolicyAndGuidance/DH_4009474). Accessed 22 August 2011.

Dunner D (2003). Clinical consequences of under-recognised bipolar spectrum disorder. Bipolar Disorders 5, 456-463.

Fagiolini A, Kupfer DJ, Rucci P, Scott JA, Novick DM, Frank E (2004). Suicide attempts and ideation in patients with bipolar I disorder. Journal of Clinical Psychiatry 65, 509-514.

Gonda X, Pompili M, Serafini G, Montebovi F, Campi S, Dome P, Duleba T, Girardi P, Rihmer Z (2012). Suicidal behavior in bipolar disorder: epidemiology, characteristics and major risk factors. Journal of Affective Disorders 143, 16-26.

Goodwin FK, Jamison KR (1990). Manic-Depressive Illness. Oxford University Press: New York, NY.

Guze SB, Robins E (1970). Suicide and primary affective disorders. British Journal of Psychiatry 117, 437-438.

Harris EC, Barraclough B (1997). Suicide as an outcome for mental disorders: a meta-analysis. British Journal of Psychiatry 170, 205-228.

Hawton K, Sutton L, Haw C, Sinclair J, Harris L (2005). Suicide and attempted suicide in bipolar disorder: a systematic review of risk factors. Journal of Clinical Psychiatry 66, 693-704.

Hunt I, Kapur N, Robinson J, Shaw J, Flynn S, Bailey H, Meehan J, Bickley H, Parsons R, Burns J, Amos T, Appleby L (2006). Suicides within 12 months of contact with mental health services in different age and diagnostic groups: a national clinical survey. British Journal of Psychiatry 188, 135-142.

Isometsä ET, Henriksson MM, Aro HM, Heikkinen ME, Kuoppasalmi KI, Lonnqvist JK (1994). Suicide in major depression. American Journal of Psychiatry 151, 530-536.

Isometsä ET, Heikkinen ME, Marttunen MM, Aro HM, Lonnqvist JK (1995). The last appointment before suicide: is suicidal intent communicated? American Journal of Psychiatry 152, 919-922.

Lee S, Ng K, Tsang A (2009). A community survey of the twelve-month prevalence and correlates of bipolar spectrum disorder in Hong Kong. Journal of Affective Disorders 117, 79-86.

Leverich GS, Altshuler LL, Frye MA, Suppes T, Keck PE, McElroy SL, Denicoff KD, Obrocea G, Nolen WA, Kupka R, Walden J, Grunze H, Perez S, Luckenbaugh DA, Post RM (2003). Factors associated with suicide attempts in 684 patients with bipolar disorder in the Stanley Foundation Bipolar Network. Journal of Clinical Psychiatry 64, 506-515.

Linsley KR, Schapira K, Kelly TP (2001). Open verdict v. suicide - importance to research. British Journal of Psychiatry 178, 465-468.

López P, Mosquera F, de León J, Gutiérrez M, Ezcurra J, Ramírez F, González-Pinto A (2001). Suicide attempts in bipolar patients. Journal of Clinical Psychiatry 62, 963-966.

Marangell L, Bauer M, Dennehy E, Wisniewski S, Allen M, Miklowitz D, Oquendo M, Frank E, Perlis R, Martinez J, Fagiolini A, Otto M, Chessick C, Zboyan H, Miyahara S, Sachs G, Thase M (2006). Prospective predictors of suicide and suicide attempts in 1,556 patients with bipolar disorders followed for up to 2 years. Bipolar Disorders 8, 566-575.

Merikangas K, Akiskal H, Angst J, Greenberg P, Hirschfeld R, Petukhova M, Kessler R (2007). Lifetime and 12-month prevalence of bipolar spectrum disorder in the National Comorbidity Survey Replication. Archives of General Psychiatry 64, 543-552.

Merikangas KR, Jin R, He JP, Kessler RC, Lee S, Sampson NA, Viana MC, Andrade LH, Hu C, Karam EG, 
Ladea M, Medina-Mora ME, Ono Y, Posada-Villa J, Sagar R, Wells JE, Zarkov Z (2011). Prevalence and correlates of bipolar spectrum disorder in the World Health Survey Initiative. Archives of General Psychiatry 68, 241-251.

Merikangas KR, Lamers F (2012). The 'true' prevalence of bipolar II disorder. Current Opinion in Psychiatry 25, 19-23.

Merikangas KR, Pato M (2009). Recent developments in the epidemiology of bipolar disorder in adults and children: magnitude, correlates, and future directions. Clinical Psychology: Science and Practice 16, 121-133.

Mitchell P, Slade T, Andrews G (2004). Twelve-month prevalence and disability of DSM-IV bipolar disorder in an Australian general population survey. Psychological Medicine 34, 777-785.

Nordentoft M, Mortensen P, Pedersen C (2011). Absolute risk of suicide after first hospital contact in mental disorder. Archives of General Psychiatry 68, 1058-1064.

O'Donnell I, Farmer R (1995). The limitations of official suicide statistics. British Journal of Psychiatry 166, 458-461.

Oquendo M, Mann J (2006). Suicidal behaviour in bipolar disorder: state of the biological, clinical and interventions evidence. Bipolar Disorders 8, 523-525.

Pompili M, Rihmer Z, Innamorati M, Lester D, Giradi P, Tatarelli R (2009). Assessment and treatment of suicide risk in bipolar disorders. Expert Review of Neurotherapeutics 9, 109-136.

Rihmer Z (2005). Prediction and prevention of suicide in bipolar disorder. Clinical Neuropsychiatry 2, 48-54.
Rihmer Z (2007). Suicide risk in mood disorders. Current Opinion in Psychiatry 20, 17-22.

Rihmer Z (2009). Suicide and bipolar disorder. In Bipolar Depression: Molecular Neurobiology, Clinical Diagnosis and Pharmacotherapy (ed. C. A. Zarate and H. K. Manji), pp. 47-56. Birkhauser Verlag: Switzerland.

Simon GE, Hunkler E, Fireman B, Lee JY, Savarino J (2007). Risk of suicide attempt and suicide death in patients treated for bipolar disorder. Bipolar Disorders 9, 526-530.

ten Have M, Vollebergh Bijl R, Nolen W (2002). Bipolar disorder in the general population in The Netherlands (prevalence, consequences and care utilisation): results from The Netherlands Mental Health Survey and Incidence Study (NEMESIS). Journal of Affective Disorders 68, 203-213.

Tondo L, Isacsson G, Baldessarini R (2003). Suicidal behaviour in bipolar disorder: risk and prevention. CNS Drugs 17, 491-511.

Tondo L, Lepri B, Baldessarini R (2007). Suicidal risk among 2826 Sardinian major affective disorder patients. Acta Psychiatrica Scandinavica 116, 419-428.

US Public Health Service (1999). The Surgeon General's call to action to prevent suicide 1999 (www.surgeongeneral. gov/library/calltoaction/calltoaction.htm). Accessed 17 October 2011.

Windfuhr K, While D, Hunt I, Turnbull P, Lowe R, Burns J, Swinson N, Shaw J, Appleby L, Kapur N (2008). Suicide in juveniles and adolescents in the United Kingdom. Journal of Child Psychology and Psychiatry 49, 1155-1165. 